\title{
A construção de uma "verdadeira nação no Brasil": nacionalismo, autoritarismo e corporativismo
}

\author{
The building of the "truthful Brazilian nation": nationalism, authoritarianism, \\ and corporatism
}

La construción de una "verdadera nación Brasileña": nacionalismo, autoritarismo

y corporativismo

Luciano AronneAbreu ${ }^{*}$

\section{Resumo}

Entre as décadas de 1920 e 1940 foram correntes no Brasil os debates políticos e intelectuais sobre a construção da "verdadeira nação brasileira" e de um país moderno e desenvolvido, tendo por referência os casos de diferentes países europeus e dos Estados Unidos. Sobre esses debates, destaca-se neste estudo o pensamento de Francisco José de Oliveira Viana, que produziu expressivas obras entre 1920 e 1951, ano de morte desse. De um lado, considerando-se o conjunto de sua obra, o objetivo deste estudo é analisar de que modo Oliveira Viana definia as ideias de nacionalismo, autoritarismo e corporativismo, destacando seus diferentes sentidos e relações mútuas para a construção de uma "verdadeira nação brasileira". De outro, este estudo também se propõe a identificar as possíveis convergências entre suas concepções e o sistema político brasileiro vigente durante os anos Vargas (19301945).

Palavras-chave: Nacionalismo. Autoritarismo. Corporativismo.

Ao longo de sua obra, de caráter não apenas teórico, mas fortemente pragmático, Oliveira Viana tinha como um dos seus principais objetivos formular o projeto de um novo Estado e de uma nova diretriz política

Doutor em História Latino-Americana pela Unisinos. Professor do curso de História e do Programa de Pós-Graduação em História da PUCRS.

Recebido em 01/07/2014 - Aprovado em 25/02/2015 http://dx.doi.org/10.5335/hdtv.15n.1.5289 
capaz de construir, no Brasil, uma nação solidária. A esse respeito, Nilo Odália diz que Viana manteve em seus trabalhos a busca da unidade nacional, iniciada por Varnhagen em princípios do século XIX. Porém, ao contrário da insistência desse na "pretensa homogeneidade" e "unidade" da sociedade brasileira, o que o levou a camuflar sua diversidade e "distorcer a realidade histórica", Odália diz que Viana teria aprendido a "lição de Capistrano de Abreu", qual seja, a de que se deve destacar a diversidade brasileira e a crença de que:

[...] é no espaço brasileiro que se deve buscar uma das peculiaridades do modo de ser brasileiro e um dos grandes modeladores do que ele chama de caráter nacional (ODÁLIA, 1997, p. 131).

Nesse sentido, o latifúndio se constituiria, para Oliveira Viana, no principal modelador da nossa identidade e das nossas diferenças em relação aos outros povos, ao mesmo tempo constituindo-se também na origem e na fonte dos maiores males de que o Brasil padece e que o impedem de ser uma "verdadeira nação". Entretanto, deve-se aqui observar que, em nenhum momento, Oliveira Viana define de forma clara e direta o que vem a ser para ele uma nação, ou uma "verdadeira nação". Ainda assim, parece ser consensual entre os intérpretes de Viana que a insolidariedade resultante da dispersão dos latifúndios seria o maior impedimento à unidade nacional do Brasil e, portanto, em sentido inverso, sua ideia de nação estaria ligada exatamente à solidariedade social, a qual se colocaria em oposição "a qualquer outra que não seja a que tem como fundamento o interesse coletivo" (ODÁLIA, 1997, p. 135). Nesses termos, a formação de uma sociedade solidária, ou de uma "verdadeira nação" brasileira, somente seria possível com a correção dos inconvenientes da "extraordinária latitude" do país, pela ação efetiva do Estado e da maior circulação das suas instituições por todo o território. Só o Estado seria capaz de unificar as diferentes regiões brasileiras (Norte, Centro-sul e Extremo-sul) e construir uma nação verdadeiramente solidária. O meio para isso, como destaca Ângela de Castro Gomes, seria a organização da sociedade em sindicatos, segundo um modelo corporativo, ou seja, "a geração de solidariedade por meio dos interesses comuns das profissões" (2010, p. 209). O corporativismo, portanto, seria uma espécie de resposta de Oliveira Viana ao seu diagnóstico do insolidarismo, sendo a "verdadeira nação" brasileira de tipo corporativo, como se verá melhor a seguir.

\section{Corporativismo como ideal de nação}

Se o corporativismo se coloca para Oliveira Viana como seu ideal de nação para o Brasil ou, pelo menos, como condição para a construção do que o autor chama de uma "verdadeira nação solidária", isso se deve às singulares condições de nossa formação histórica e à incapacidade do povo de se organizar de forma autônoma em defesa dos interesses coletivos, cabendo esse papel ao Estado, por meio da ação de sindicatos e corporações profissionais a ele subordinados. De um lado, considerando-se que Oliveira Viana se propunha a produzir um conhecimento objetivo e científico sobre o Brasil, o autor voltou-se para o passado em busca 
das raízes de nossos problemas e das nossas singularidades em relação às outras nações; de outro, contudo, considerando-se o "caráter engajado ou fundante" da sua análise, Oliveira Viana utilizou-se da história para justificar o papel que atribuía ao Estado na construção da nação e o modelo corporativo por ele proposto. Na definição de Nilo Odália, sua história seria fundante porque

[...] passa a ser o fundamento, a origem e, mesmo, a explicação de projetos e de medidas políticas práticas de um indivíduo, de uma empresa, de um Estado, para atingir fins determinados (ODÁLIA, 1997, p. 121).

Ora, tendo-se em vista que, na ótica de Oliveira Viana, o Brasil ainda não era uma unidade constituída, mas uma unidade a constituir-se, pode-se dizer que o caráter pragmático e fundante da sua história não deve ser compreendido apenas a partir do seu olhar para o passado, mas, especialmente, da sua visão de futuro. Se o passado justifica as nossas singularidades e a ação do Estado, a "verdadeira nação" brasileira estaria no porvir. Por sua vez, o novo Estado corporativo a ser construído também teria por fundamento o passado, dadas as peculiares condições da formação social e cultural do povo brasileiro. De alguma forma, portanto, esse passado se faria presente de modo permanente em nossa sociedade, tanto como justificativa das ações do Estado vigente como do seu futuro modelo corporativo.

A esse respeito, Bernardo Ricupero observa que o pensamento conservador clássico associa ao passado e à história, não exatamente a ideia da sucessão, mas a da coexistência. Já no caso de Oliveira Viana, diz Ricupero, ainda que essa mesma ideia seja válida, esse autor apresenta uma ambiguidade em relação a dois momentos do passado brasileiro, o colonial e o da independência (RICUPERO, 2010, p. 80). Assim, Viana idealiza o passado colonial ao sugerir, por exemplo, "que a colonização do Brasil teria sido realizada por fidalgos provenientes dos ramos mais ilustres da nobreza portuguesa" (RICUPERO, 2010, p. 81). De outro modo, porém, dada a autossuficiência dos latifúndios, essa aristocracia da terra não teria sido capaz, após a independência, de realizar a obra de unificação nacional. Nos tempos monárquicos, essa obra teria sido realizada pela ação da Coroa e, na República, seria feita pela ação de um Estado autoritário, de tipo corporativo.

Sobre o Estado, deve-se observar que Oliveira Viana tem uma concepção altamente pragmática do seu papel, "a tal ponto que não é excessivo dizer-se que esse se comporta, em relação à realidade, aos seus fins e às suas atribuições, como um verdadeiro camaleão, cujas cores se alternam, segundo as necessidades da situação histórica sobre a qual deve atuar ou submeter-se" (ODÁLIA, 1997, p. 141). De um lado, como destaca Nilo Odália, o Estado deverá submeter-se à relaidade onde a solidariedade social é uma decorrência natural do meio geográfico; de outro, o Estado deverá impor novas cores quando a realidade histórica tiver que ser "desobedecida e amestrada" para se criarem as condições necessárias à solidariedade. Esse Estado camaleônico, porém, não agiria por um "ato de vontade arbitrário", mas como uma consequência racional, no caso do Brasil: 
[...] da passagem de uma situação colonial, modelada pelo espaço brasileiro, a uma nova situação de país independente, onde os inconvenientes do fator geográfico e a sequela daí decorrente devem ser dominados, a fim de que se possa construir a nação solidária socialmente (ODÁLIA, 1997, p. 142).

Ainda que se esteja de acordo com Odália quanto à inexistência de uma teoria do Estado na obra de Oliveira Viana e o caráter essencialmente pragmático de sua concepção a esse respeito, pode-se dizer que a discussão sobre a presença ou a ausência do Estado na história brasileira, desde os tempos coloniais até a República, se constitui no fio condutor por excelência de sua obra ${ }^{1}$. $\mathrm{O}$ mesmo pode ser dito quanto à constante preocupação de Oliveira Viana em buscar no passado as singularidades do povo brasileiro em relação a outros povos, destacando seu caráter rural e sua insolidariedade social. Outro é o caso, porém, da sua proposta de construção no país de um Estado forte e de tipo corporativo ${ }^{2}$, que se constituiria não exatamente num fio condutor de sua obra, mas numa espécie de ponto de chegada de um novo Brasil, uma resposta ao seu diagnóstico de insolidarismo. Nesse caso, deve-se destacar que suas referências ao corporativismo apareceriam somente a partir de 1930, quando Viana atuou também como Consultor Jurídico do Ministério do Trabalho, fazendo dele "um dos statemakers do período", como define Gomes (2009, p. 156).

A esse respeito, sintetizando sua visão sobre o caráter camaleônico do Estado e sua necessidade de submeter-se ou de impor-se à realidade nacional, Oliveira Viana dizia que os estadistas coloniais
[...] haviam chegado à fórmula: integridade da colônia pela fragmentação do poder. Os estadistas imperiais são levados a uma conclusão contrária: integridade do país pela unificação do poder. Os estadistas republicanos voltam à conclusão colonial: integridade da nação pela fragmentação do poder (VIANA, 1923, p. 242).

Porém, já em princípios dos anos 1920 se observava no país o sentimento da incapacidade das administrações estaduais e o desejo de formação de um novo Estado centralizado:

Por toda parte se difunde e radica o sentimento contrário: o sentimento da superioridade do governo federal como força incomparável de organização, coordenação e administração (VIANA, 1923, p. 268-269).

Já em princípios dos anos 1930, o autor irá destacar a importância das corporações e dos conselhos técnicos, dizendo que o seu papel era trazer aos centros do governo e da administração

[...] a colaboração de todos os homens [...] práticos, experientes, que, embora não pertencendo à classe política, estejam, contudo [...] em contato mais direto com a nossa realidade [...] (VIANA, 1930, p. 7-8).

Nesse sentido, portanto, destaca-se o olhar de Oliveira Viana para o passado e para o futuro do Brasil, não apenas com vistas a compreender as singularidades apontadas pelo autor em relação ao nosso passado colonial, mas especialmente o modo como ele justifica as permanências e as necessárias rupturas com esse passado por meio da ação de um Estado forte e das corporações, em nome da construção de uma "verdadeira nação" solidária no país. 
Ao olhar para o passado, Viana diz que "somos distintos dos outros povos, principalmente dos grandes povos europeus, pela história, pela estrutura, pela formação particular e original" (VIANA, 1920, p. III). Em outras palavras, pode-se dizer que a singularidade brasileira não seria diretamente associada pelo autor a uma característica social, política ou cultural específica, mas que essa seria o resultado de um conjunto de fatores históricos (ligados à nossa história colonial) estruturais, condicionados pelas relações e determinações entre o meio físico e o homem; pela formação particular e original de nossa sociedade - marcada pelo insolidarismo - e pelo domínio dos clãs rurais. Ainda que de formas distintas, a afirmação da singularidade brasileira se constitui numa constante preocupação de Oliveira Viana ao longo de toda sua obra, numa espécie de ponto de partida para sua argumentação posterior.

Ao longo dos anos 1920, especialmente em Populações Meridionais do Brasil (1920), Oliveira Viana se propôs a desvendar nossa singularidade, construindo uma história que é, ao mesmo tempo, geral (mas não completa) e parcial, como define Luiz de Castro Faria. Como "história geral", estende-se dos tempos coloniais até fins do Segundo Império; como "história parcial", distinguem-se três histórias diferentes do Brasil: a do norte, a do centro-sul e a do extremo-sul (FARIA, 2002, p. 51). Em relação à sua "história geral", Viana destaca como principais características para distinguir o Brasil dos outros povos sua origem rural, a insolidariedade e o espírito de clã; em relação à sua "história parcial", o autor observa o caráter regional das histórias do norte (sertanejo) e do extremo-sul (gaúcho), ao contrário do caráter nacional da história do centro-sul (matuto) que, a partir da ação dos bandeirantes e de sua proximidade com o centro do poder, se constituiria na base para a construção da "verdadeira nação brasileira".

Ainda nos anos 1920, em sua obra $O$ Idealismo na evolução política do Império e da República (1922), Viana definiria como "idealistas utópicos" os nossos políticos liberais que, ao elaborar os nossos códigos e leis, não observam nossas singularidades, "não levam em conta os dados da experiência"; ao contrário dos chamados "idealistas orgânicos", de formação política conservadora, cuja ação "só se forma de realidade, que só se apoia na experiência, que só se orienta pela observação do povo e do meio" (1922, p. 17-18).

Já a partir da década de 1930, quando Oliveira Viana se torna um statemaker do regime varguista, suas obras passam a ter cada vez mais a preocupação de propor soluções aos problemas por ele identificados, não mais formulando diagnósticos, mas se dedicando à implantação de políticas públicas por meio da intervenção de um Estado autoritário e corporativo, como bem define Gomes (2009, p. 150). Suas referências ao passado, portanto, não têm mais a preocupação de desvendar nossas singularidades, mas o conhecimento dessas se constitui num pressuposto para a ação de nossas elites políticas e do Estado, daí a insistência do autor em contrapor o "idealismo utópico" do liberalismo vigente no Brasil até fins dos anos 1920 ao "idealismo orgânico" que en- 
tão começava a se implantar com o regime de Vargas.

Sobre o caráter rural da sociedade brasileira, sua singularidade estaria no fato de que, ao contrário dos pequenos proprietários peninsulares, nossos homens do campo são detentores de grandes latifúndios, o que se constituiria num traço fundamental de "nossa psicologia nacional" e da própria estrutura da sociedade, marcada pela insolidariedade e pelo espírito de clã. $\mathrm{O}$ instinto urbano não estaria em nossa índole, diria Viana a respeito do povo brasileiro, em geral, e de suas elites, em particular. Nesse sentido, como já referido a respeito de sua visão do passado colonial e o da independência, Oliveira Viana se mostraria ambíguo também em relação aos latifúndios, por ele associados diretamente à gênese da nacionalidade e dos mestiços e, ao mesmo tempo, à extrema simplificação e fragmentação da vida social e econômica brasileira, que impedia sua verdadeira unidade. Segundo ele, os latifúndios teriam impedido a formação das classes comercial, industrial e, até mesmo, de corporações urbanas no Brasil, viabilizando apenas o domínio dos grandes senhores rurais. Em suas palavras,

[...] na amplíssima área de latifúndios agrícolas, só os grandes senhorios rurais existem. Fora deles tudo é rudimentar, informe, fragmentário. São os grandes domínios como que focos solares: vilas, indústrias, comércio, tudo se ofusca diante de sua claridade poderosa (VIANA, 1920, p. 130).

Em relação ao homem, seja ele de origem mestiça ou um "ariano puro", do povo ou da aristocracia rural, Oliveira Viana se manifestaria de forma não menos ambígua do que aquela sobre sua visão do passado e do meio físico brasileiro. Quanto aos mestiços, tidos pelo autor como produto histórico dos latifúndios, Viana diria que sua "facilidade de emigração" dera uma importante contribuição para a construção da nacionalidade. Porém, esse mesmo fator teria favorecido a "desorganização de nossa sociedade e do nosso povo" (VIANA, 1920, p. 133). Isso porque, segundo a lógica argumentativa de Viana, sendo a terra o principal meio de qualificação social na colônia e os escravos sua mão de obra por excelência, os laços entre os trabalhadores livres (mestiços) e os grandes senhores rurais seriam muito fluidos, favorecendo sua emigração e a expansão da estrutura social e econômica dos latifúndios para outras regiões. Entretanto, tal emigração favoreceria também a não fixação do homem à terra, constituindo-se então num importante fator de dispersão e de fragmentação social, em causa da insolidariedade e da ausência de classes organizadas no Brasil, segundo Viana. Já os grandes proprietários rurais constituiriam "a única classe realmente superior do país, aquela em que se concentra a maior soma de autoridade social" (VIANA, 1920, p. 34). Mais do que autoridade social, por sua origem ariana, a família patriarcal seria, para Viana, "a mais bela escola de educação moral do nosso povo" (1920, p. 42), possuindo qualidades essenciais que se refletiriam na própria mentalidade brasileira, quais sejam, a fidelidade à palavra dada, probidade, respeitabilidade e independência moral. Esses grandes senhores rurais seriam na colônia a força dirigente dos latifúndios, sua cabeça. 
Nas palavras de Viana, "daí é que partem as ações, de cuja trama se faz a história colonial" (1920, p. 65). Em sua relação com o povo, os senhores rurais não seriam nunca seus opressores, mas seus protetores, “[...] o seu amigo, o seu chefe admirado e obedecido. Nunca o seu inimigo, o seu antagonista, o seu opressor" (1920, p. 312).

Nos tempos coloniais, dados os objetivos essencialmente econômicos e fiscais da Coroa portuguesa, a autossuficiência dos latifúndios e o poder concentrado pelos grandes senhores rurais seriam favorecidos pela completa ausência ou, no mínimo, pelo distanciamento do Estado português de sua colônia brasileira. Naquele contexto, conforme Viana, observa-se que a marcha do poder público é mais demorada que a da massa social, "cujos movimentos incumbem a ele regular e dirigir". Assim, "há uma visibilíssima discordância, ainda hoje sensível, entre a área demográfica e a área política, entre a área da população e o campo de eficiência da autoridade pública" (VIANA, 1920, p. 210). A grande mobilidade das bandeiras e do regime pastoril, ocupando regiões cada vez mais extensas de território brasileiro, não seria acompanhada da ação correspondente do Estado em instalar nessas novas regiões seus órgãos administrativos, de justiça e segurança, daí resultando a chamada "anarquia branca". Para Viana, as bandeiras são como um fragmento do latifúndio, levando consigo todos os seus elementos formadores - "o senhor, os escravos, a tropa aguerrida dos mamelucos e, quase sempre, o capelão que oficia na Igreja do senhorio" (VIANA, 1920, p. 79) -, trasladando, assim, integralmente o domínio rural para as novas terras descobertas. Porém, dada a pouca mobilidade do poder público, as populações do interior são levadas a se concentrar em torno da nobreza rural para se proteger da anarquia branca: a incapacidade da justiça de assegurar aos moradores a integridade do seu patrimônio; o modo arbitrário de exercício do poder pelos capitães-mores, que "se fazem os pequenos ditadores das localidades" (1920, p. 153); o facciosismo das corporações municipais; e o recrutamento compulsório, por exemplo.

Em tais condições, portanto, estando ausentes a solidariedade de classes e a proteção do Estado, Viana diz que aos "cidadãos sem fortuna" restaria apenas buscar apoio e proteção nos fazendeiros locais, constituindo-se, assim, o que ele define como "espírito de clã' e "solidariedade de clã", uma das singularidades brasileiras que se faria presente em nossa sociedade mesmo após a independência e a república. Ainda no período colonial, Viana vê nessas características o resultado de uma obra "de admirável senso prático" dos estadistas coloniais, inspirados "em dados concretos e experimentais" e em "permanente contato com as nossas realidades" (1923, p. 238), de acordo com os já citados objetivos lusitanos. Após a independência, porém, elas se constituiriam em entraves à união nacional, sendo necessário ao Estado agir com base nessa realidade histórica, mas sem se submeter a ela, de modo a construir a verdadeira nação brasileira.

Nesse sentido, nos tempos monárquicos, caberia ao Estado a responsabilidade de organizar a ordem legal e consolidar a unidade da nova nação. De acordo com Viana, essas tarefas caberiam a um Estado centrali- 
zado, "com um governo nacional poderoso, dominador, unitário, incontrastável, provido de capacidades bastantes para realizar, na sua plenitude, os seus dois grandes objetivos capitais: a consolidação da nacionalidade e a organização da sua ordem legal" (1920, p. 344). Assim, consolidar a nacionalidade e organizar a nova ordem legal do país dependia da capacidade do Estado de impor-se sobre as diferentes regiões e localidades e de limitar o poder das oligarquias rurais, atraindo-as para sua própria órbita. De outro modo, porém, a consolidação e a estabilidade desse poder central dependiam muito mais do poder e do prestígio pessoal do monarca que das instituições monárquicas, em si, devido aos traços próprios da cultura nacional, historicamente marcada pela submissão ao chefe e pela ausência de um sentimento coletivo ou nacional.

A esse respeito, destacando o papel do rei sobre o próprio Estado, Viana diz que no século IV ele é

[...] o agente mais prestigioso, mais enérgico, mais eficaz do sincretismo nacional. $\mathrm{O}$ poder central deve a ele, com a sua unidade e a sua ascendência, a sua consolidação e estabilidade (1920, p. 249).

O rei seria então o "regulador supremo do jogo dos partidos, o grande dominador dos clãs, o repressor da caudilhagem nacional" (1920, p. 254). Em suma, citando a máxima do Visconde de Itaboraí, Oliveira Viana diz que nesse período o "rei reina, governa e administra", de acordo com o princípio do poder pessoal do monarca. Ainda sobre o poder do monarca, mas dessa vez destacando a importância da ação pessoal de D. Pedro II, Oliveira Viana afirma que:
[...] ele é o único que compreende a realidade das nossas coisas, a nossa incultura política, a artificialidade dos nossos partidos, a impossibilidade de praticar-se aqui, na sua pureza, o belo regime que fez a glória da nação inglesa [...] (1920, p. 262).

Desse modo, D. Pedro II deturpa esse regime e constrói um parlamentarismo à brasileira, dando ao Brasil

[...] meio século de paz, de tranquilidade, de ordem. Meio século de legalidade, de justiça, de moralidade. Pela atração da majestade imperial, contém o centrifugismo das Províncias. Pela ascendência do seu poder pessoal, corrige a hostilidade, a intransigência, o exclusivismo das facções políticas (VIANA, 1920, p. 262).

Já em fins do século XIX, embora a República receba do velho regime "uma nação pacificada, tranquila, obediente, organizada, progressiva, moralizada" (VIANA, 1923, p. 217), os estadistas republicanos voltam ao modelo colonial de integração da nação pela fragmentação do poder: "livres do fascínio imperial, é a vez dos fatores geográficos reivindicarem seus direitos" (VIANA, 1923, p. 242), sendo o regime federativo o meio de evitar a secessão do país. Isso porque, segundo Viana, o mecanismo de centralização do poder monárquico estava assentado mais no "sentimento de fidelidade ao Imperador, de veneração à sua pessoa, de admiração carinhosa pelas suas altas virtudes e pelos seus hábitos democráticos" do que na monarquia, propriamente dita, pois em verdade "o povo não é monarquista, como também não é republicano; é inteiramente indiferente às formas de governo" (1923, p. 240). A República, portanto, teria agravado no Brasil a instabilidade iniciada com a 
abolição da escravidão, as quais teriam não apenas provocado o abalo da sua estrutura produtiva e o abandono do campo por muitos senhores rurais, mas, também, provocado a quebra dos velhos quadros políticos e partidários lentamente formados ao longo de 50 anos de regime monárquico (1923, p. 245). A respeito do modelo político do novo regime, Viana diz que a República "coloca em posição subalterna o poder central diante dos poderes estaduais [...]" (1923, p. 244). Em suma, "essa formidável onipotência dos presidentes de Estado obriga os Presidentes da República a uma política de transações com as diversas situações dominantes nos Estados" (1923, p. 252).

Tal modelo federativo, porém, mesmo que o autor nele reconheça o papel de evitar a secessão do país, seria visto por Oliveira Viana como inadequado à realidade nacional, fruto do "idealismo utópico" dos nossos estadistas republicanos. Esses seriam

[...] excelentes tradutores de males estranhos; péssimos intérpretes dos nossos próprios males. É natural, pois, que a sua obra máxima - a Constituição Federativa não tenha sido outra coisa senão uma obra [...] votada ao fracasso imediato (VIANA, 1927, p. 26-27).

Isso porque essa Constituição estaria assentada em princípios que não tem nenhuma objetividade na realidade nacional, como a existência de uma opinião pública organizada que se expressaria por meio dos partidos políticos e do voto. Assim, o problema político fundamental do Brasil não estaria em organizar o voto, e, sim, em organizar a opinião, sendo a democracia definida por Viana justamente como "o governo da opinião" (1927, p. 87).

Nesse sentido, conforme Viana (1939), na segunda edição de $O$ Idealismo da Constituição, a democracia adequada à realidade brasileira não seria fundada no princípio da liberdade, que se basearia justamente na existência de uma opinião organizada e de verdadeiros partidos políticos, mas aquela fundada no princípio da autoridade, ou seja, uma democracia autoritária. A esse novo Estado autoritário, portanto, caberia exatamente organizar as classes e a opinião pública no Brasil, colocando-se como o único e legítimo representante dos interesses nacionais, acima dos interesses de clãs. De acordo com esse novo modelo "democrático", a peça mais importante do sistema não seria o Parlamento, mas o presidente da República, instituindo-se o que Viana chama de primado do Executivo, em que o presidente é a autoridade suprema do Estado, ficando livre da "dependência humilhante do Parlamento" (1939, p. 133). Ainda assim, as bases do governo e da administração seriam ampliadas pela democracia autoritária com o reconhecimento de novas fontes de opinião que não os partidos políticos, tais como os conselhos técnicos, as associações de classe e os sindicatos. Desse modo, o caráter democrático do governo se revelaria não pela representação parlamentar ou pelo voto, mas pela garantia dos direitos do cidadão e pelo apelo direto do Presidente da República à opinião pública, por meio de suas corporações. Segundo Viana, 
[...] o espírito da nova organização é de pouca confiança na opinião das assembléias [sic] políticas, de pura formação partidária, e de maior confiança na opinião das corporações profissionais, de base e inspiração econômica ou cultural (1939, p. 169).

Em outras palavras, pode-se dizer que essa democracia autoritária seria de tipo corporativo, sendo esse não apenas o meio mais adequado para a organização das classes e da opinião pública no Brasil, mas também condição para se atingir o esperado fim da construção de uma "verdadeira nação" brasileira. A esse respeito, em primeiro lugar, deve-se observar que, embora Oliveira Viana, desde Populações meridionais do Brasil (1920), já defendesse a necessidade de se implantar no país um modelo de Estado centralizado e autoritário, seria somente a partir de O Idealismo da Constituição (1927) que o autor passaria a sugerir a associação desse Estado a princípios corporativistas. Nessa obra, considerando sua definição de que a democracia é o "governo da opinião", Oliveira Viana destacaria a importância de nossas classes econômicas se organizarem e praticarem a solidariedade. Em suas palavras:

[...] se esta solidariedade puder um dia ser conseguida, poderemos esperar tranqüilos [sic] o advento da Democracia no Brasil. [...] Porque a pedra de toque da possibilidade do governo do povo pelo povo em nosso país está nisto: na capacidade das nossas classes produtoras de organizarem-se economicamente (VIANA, 1927, p. 117).

Em segundo lugar, deve-se ainda observar que não há exatamente uma teoria do corporativismo na obra de Oliveira Viana, nem mesmo uma preocupação do autor em elaborar uma concepção de corporativismo específica para o Brasil, mas, tão somente, em propor, com base nos seus princípios, alternativas à nossa insolidariedade social e à falta de sentimento coletivo que impediam a formação de uma "verdadeira nação" no país e seu desenvolvimento.

Dito isso, quais seriam então as formas propostas pelo autor para organizar a opinião e a nova democracia autoritária ou corporativa no Brasil? Quanto à definição do seu modelo de corporativismo, Oliveira Viana toma como referência o caso europeu para destacar a tendência de sua época à especialização técnica, à organização das classes econômicas e ao declínio dos, por ele chamados, "parlamentos oniscientes". De outro modo, porém, ele observa que o Brasil não estaria ainda preparado para adotar esse modelo, que talvez não fosse mesmo adequado à nossa realidade, sendo então necessário construir um modelo próprio. De todo modo, referindo-se às tendências corporativas de sua época, já em 1930, Oliveira Viana dizia que "as grandes classes econômicas" deveriam se colocar em condições de exercer os poderes públicos no Brasil, em que a competência parlamentar deveria ser substituída pela competência técnica. Naquele contexto, porém, dizia que, no Brasil, ainda havia muita gente que acreditava com sinceridade

[...] que um mocinho qualquer, de anel de rubi no dedo, só pelo simples fato de acontecer ter sido nomeado deputado, fica por isso mesmo, sem mais nada, com a competência para discutir ou elaborar uma lei sobre a metalurgia do ferro ou sobre a profilaxia antipalúdica" (VIANA, 1930, p. 158). 
No caso europeu, ao citar o exemplo de países como Itália, França, Bélgica e a Inglaterra "dos parlamentos onipotentes", como Oliveira Viana a ela se refere, o autor observa que o caráter técnico e corporativo dos seus governos seria uma nova tendência legislativa dos Estados modernos. No caso brasileiro, contudo, ele destaca a inexistência de espírito corporativo e de organização de classes, afirmando que: "é bem possível que nenhum desses sistemas nos sirva e que tenhamos mesmo de engenhar um sistema nosso, ao nosso jeito, uma solução própria, adaptada ao nosso meio; como é possível também que não engenhemos solução ou sistema algum", mas nos resignemos em aplicar em escala modesta esses "largos e ousados métodos de política contemporânea" (1930, p. 181-182).

Nesse sentido, portanto, ao admitir a inadequação dos modelos europeus ao caso brasileiro, bem como a possível incapacidade de nossa sociedade em adequá-los de forma autônoma à realidade nacional, Oliveira Viana propõe, especialmente em suas obras Problemas de direito corporativo (1938) e Problemas de direito sindical (1943), um novo modelo de organização do Estado no Brasil, de tipo nacionalista e autoritário, uma espécie de "corporativismo de Estado". Desse modelo, destaca-se a importância que Oliveira Viana atribui nessas obras aos sindicatos e sua capacidade regulamentadora, bem como à Justiça do Trabalho e sua competência normativa.

Quanto aos sindicatos ${ }^{3}$, Viana argumenta que só por meio deles se poderia constituir e desenvolver em nosso povo
[...] aquilo que as forças da nossa história não permitiram que constituíssemos e desenvolvêssemos: os hábitos de cooperação e de ação coletiva, bem como a consciência do enorme poder da solidariedade social (1943, p. IX).

Os sindicatos, portanto, se constituiriam, para Viana, em importantes meios de educação e de organização da sociedade brasileira e, ao mesmo tempo, em novos canais de atuação das diferentes classes econômicas junto ao Estado. Assim, de acordo com o que Viana dizia serem as condições e necessidades próprias da realidade brasileira, a legislação sindical por ele proposta determinou a criação de sindicatos únicos por ofício no Brasil. Em sua opinião, o sindicato de ofício seria o ideal "para a organização de povos como o nosso, sem instituições, nem tradições de solidariedade econômica ou profissional", visto que sua homogeneidade de composição permitiria

[...] cristalizar mais rapidamente, entre os seus associados, uma forte consciência de unidade e de grupo e, em consequência, um sentimento mais lúcido e militante dos interesses coletivos da categoria a que pertencem (1943, p. X).

A unicidade sindical se justificaria, segundo Viana, porque a legislação reconheceu os sindicatos e suas convenções coletivas como válidas para toda a categoria profissional, e não apenas para os seus associados. Do contrário, "teríamos um caso de dupla personalidade legal. [...] O fato de ter a Constituição dado às Convenções Coletivas o caráter de um regulamento da categoria implica, sem dúvida, no reconhecimento do sindicato único". Ou, então, "teríamos a 
possibilidade de várias convenções coletivas regulando diversamente a mesma matéria para a categoria inteira - o que seria absurdo" (VIANA, 1943, p. 4-5).

Em tais condições, ainda conforme Viana, os sindicatos no Brasil não seriam apenas associações privadas, mas assumiriam também atributos de direito público, tornando-se uma associação sui generis,

[...] colocada numa situação que a situa abaixo das instituições administrativas do Estado, mas acima do vasto mundo das associações privadas, sobre as quais o Estado não tem propriamente nenhum interesse de controle direto e imediato (1943, p. 6-7).

Dessa forma, os sindicatos seriam tirados da "penumbra da vida privada" para "as responsabilidades da vida pública", de modo que esse amplo movimento de sindicalização é conduzido pelo Estado Novo "o primeiro passo para a organização social do nosso povo" (1943, p. VI-VII). Assim, é por meio dos sindicatos que as nossas classes econômicas - empregados e empregadores

[...] irão efetivamente - e não teoricamente, como até agora - participar do Estado, penetrar nos seus conselhos e corporações e neles realizar a afirmação democrática da sua vontade e dos seus interesses (VIANA, 1943, p. XI).

Já em relação à Justiça do Trabalho ${ }^{4}$, referindo-se à polêmica sobre o art. 122 do projeto de sua criação, Oliveira Viana observa que esse a instituiu "sobre bases tipicamente corporativas", o que teria sido mal compreendido pelos juristas de tradição liberal que, segundo ele, reduzem o debate
[...] à simples condição de um mero problema de técnica jurídica, resolvidos por meios de análises e confrontos, puramente gramaticais, dos textos constitucionais e com critérios, de si mesmos absolutamente inadequados, de Direito Privado (1938, p. 38-39).

Ao contrário disso, a ordem jurídica contemporânea - com suas instituições novas, com seu Direito Social e seu Direito Corporativo - "reflete as tendências mais íntimas da vida econômica e modela-se por elas". Segundo Viana, tratava-se então de obedecer a uma

[...] tendência à organização, à uniformização, à regulamentação, à disciplina comum e coletiva - e de que a nossa política do café e do açúcar é apenas um exemplo modestíssimo (1938, p. 119-120).

Nesses termos, portanto, a Justiça do Trabalho teria por objetivo não apenas julgar os conflitos de trabalho de acordo com a nova legislação social do país, mas também mediar e até mesmo normatizar as relações entre patrões e empregados. Para tanto, em vez de ater-se à mera aplicação da técnica jurídica, como acima referido, Oliveira Viana sugere que a recém-criada Justiça do Trabalho no Brasil deveria basear-se nos princípios da chamada sociologia jurídica americana, citando especificamente o conceito de "justiça sem lei", de Roscoe Pound.

Segundo esse autor, essa nova "justiça sem lei", de caráter administrativo, se colocaria em oposição à tradicional "justiça de acordo com a lei". Isso porque, nos Estados Unidos, novos caminhos para a aplicação da lei estariam sendo criados ou admitidos pelo seu sistema legal, de modo a resolver casos particulares não definidos em lei, mas sem 
ignorar seus princípios gerais. Nesse sentido, Pound se refere à tendência crescente nos Estados Unidos de individualização da aplicação da lei por meio de diversas agências, como a justiça administrativa, as cortes especiais, as comissões, ou, mesmo, por meio de uma interpretação mais ampla e individualizada da lei pelos tribunais do país.

No Brasil, pode-se dizer que o já citado caráter normativo da Justiça do Trabalho se aproxima da ideia de "justiça sem lei" e dos tribunais administrativos definidos por Roscoe Pound. Isso porque, segundo Viana, essa Justiça corporativa atendia às necessidades próprias da moderna administração pública e suas decisões se referiam sempre a conflitos coletivos das classes, e não a demandas individuais.

Nesses termos, como o autor garante ocorrer em países como Itália, Inglaterra, Estados Unidos, Alemanha, Áustria e Austrália - por ele chamados de "mundo civilizado" - o "mandamento proibitivo quebra-se em face dos próprios imperativos da prática administrativa" (1938, p. 40). Ou seja, nesse "mundo civilizado" estaria ocorrendo um

[...] movimento geral de descentralização das atividades do Estado, dada a crescente complexidade das funções do Estado moderno, suas tendências totalitárias ou universalistas e a necessidade de reagir contra a descentralização geográfica, o que implicaria, também, numa descentralização jurídica (VIANA, 1938, p. 48-49).

Assim, pode-se dizer que o caráter normativo da Justiça do Trabalho estaria ligado tanto às novas necessidades técnicas da administração pública quanto à desconfiança da sociedade em relação aos parlamentos eminentemente políticos, que seriam inca- pazes de organizar a sociedade e de resolver seus problemas cada vez mais complexos.

A esse respeito, porém, Oliveira Viana ressalva que seu caráter normativo não é determinado pelas bases corporativas que ele também atribuiu à Justiça do Trabalho, embora ambas as coisas possam estar relacionadas no caso brasileiro. Em suas palavras, o fundamento normativo dos tribunais do trabalho não é o regime dominante num dado país, mas "é a natureza mesma da decisão, é a peculiaridade do conflito a ser julgado, é a própria estrutura das organizações econômicas contemporâneas. $\mathrm{O}$ fundamento da normatividade é orgânico - e não político" (1938, p. 94). Além disso, o caráter normativo da Justiça do Trabalho só existiria em face dos conflitos coletivos de trabalho, considerando que essa justiça é própria não para julgar questões jurídicas ou de técnica jurídica, mas apenas para os "conflitos coletivos de natureza econômica". Em termos jurídicos, portanto, com base no já citado conceito de "justiça sem lei", a Justiça do Trabalho e seus juízes teriam competências e critérios próprios em relação à Justiça comum. Nesse sentido, o diferencial das sentenças coletivas não estaria apenas no seu caráter normativo, mas também nos critérios de sua formulação, não havendo nenhum texto de lei ou de contrato no qual o juiz devesse subordinar sua decisão. A esse respeito, em síntese, Oliveira Viana argumenta que o juiz do trabalho seria uma espécie de ponderador dos interesses econômicos em conflito, sendo sua sentença coletiva "uma verdadeira arbitragem, um laudo de perito". Afinal, como julgador desses conflitos, o juiz "não se prende a nenhuma regra de direito escri- 
to, à maneira do juiz ordinário; está liberto, por assim dizer, da lei - e só tem diante de si o princípio da equidade" (1938, p. 115-116).

Face ao exposto, pode-se dizer que a "verdadeira nação" proposta por Oliveira Viana não passou de um projeto por ele proposto ao longo de sua vida e obra. Ainda que alguns de seus princípios e propostas tenham servido de referência ou até mesmo sido adotados pelo Estado Novo de Vargas, a formação de uma "verdadeira nação" e de uma "verdadeira democracia" no Brasil ainda não haviam sido consolidadas em 1952, como admite o próprio autor em sua obra Problemas de organização, problemas de direção (1952), a última escrita e concluída pelo autor ainda antes de sua morte. Em sua concepção, se cabia aos sindicatos organizar a sociedade e suas classes, à Justiça do Trabalho cabia regular e normatizar suas relações e conflitos, estando ambos ligados diretamente a um novo modelo de Estado autoritário, de tipo corporativo. No caso brasileiro, portanto, autoritarismo e corporativismo seriam condições para a construção de sua "verdadeira nação", unificada e consciente dos seus interesses coletivos.

\section{Abstract}

In the 20s and 30s, it was current in Brazil the political and intellectual debates about the building of the "truthful Brazilian Nation", and of a modern and developed country, taking as reference different cases of the European countries and the USA. About these debates, we stress the thought of Francisco José de Oliveira Viana, who produced expressive work between 1920 and 1951, when he died. On the one hand, taking as reference all of his works, the objective of this study is to analyze what Oliveira Viana understands about nationalism, authoritarianism and corporatism, stressing their possible changes of meanings and mutual relations to building the "truthful Brazilian Nation", according to Viana. On the other hand, this study also intends to identify the possible convergences and divergences between his conceptions and the Brazilian political system in the Vargas Era (1930-45).

Keywords: Nationalism. Authoritarianism. Corporatism.

\section{Resumen}

En Brasil de las décadas de 1920 a 1940 hubo muchas polémicas políticas e intelectuales acerca de la construcción de la "verdadera nación brasileña" y de un país moderno y desarrollado, teniendo por base las experiencias de distintos países europeos y la de los Estados Unidos de América. A partir de dichos debates, este estudio subraya el pensamiento de Francisco José de Oliveira Viana, y sus expresivas obras producidas a partir de 1920 hasta el año de su muerte, en 1951. Teniendo en cuenta el conjunto de su obra, el objetivo aquí es analizar de qué manera Oliveira Viana ha definido las ideas de nacionalismo, autoritarismo y corporativismo, poniendo en relieve sus distintas concepciones y mutuas relaciones para la construcción de una "verdadera nación brasileña". Por otra parte, este análisis busca identificar las posibles correlaciones entre sus concepciones y el sistema político brasileño [en vigor] de los Años de Vargas (1930-45).

Palabras clave: Nacionalismo. Autoritarismo. Corporativismo. 


\section{Notas}

Sobre a questão do Estado e a construção de uma "ideologia de Estado" no Brasil, LAMOUNIER, 2006.

2 Sobre o corporativismo no pensamento de Oliveira Viana, ver VIEIRA, 1981.

3 Sobre a questão do sindicalismo e do corporativismo no pensamento de Oliveira Viana, ver também: ABREU, Luciano Aronne de. Sindicalismo e corporativismo no Brasil: o olhar autoritário de Oliveira Viana. In: ABREU, 2013.

4 Sobre a Justiça do Trabalho e os princípios que pautaram a proposta de Oliveira Viana, ver: ABREU, 2014.

\section{Referências}

ABREU, Luciano Aronne de. Sindicalismo e Corporativismo no Brasil: o olhar autoritário de Oliveira Viana. In: ABREU, Luciano Aronne de; MOTTA, Rodrigo Patto Sá (Org.). Autoritarismo e Cultura Política. Porto Alegre: EdiPUCRS/FGV, 2013. p. 91-123.

ABREU, Luciano Aronne de. Uma "Justiça sem Lei" e Corporativa: o Brasil de Vargas e a criação da Justiça do Trabalho. Anos 90 - Revista do Programa de Pós-Graduação em História da UFRGS, Porto Alegre, v. 21, n. 39, 2014.

GOMES, Ângela de Castro. Oliveira Viana: um statemaker na Alameda São Boa Ventura. In: BOTELHO, André; SCHWARCZ, Lilia Moritz (Org.). Um enigma chamado Brasil. São Paulo: Companhia das Letras, 2009.

Oliveira Viana: o Brasil do insolidarismo ao corporativismo. In: LIMONCIC, Flávio; MARTINHO, Francisco Carlos Palomanes. Os intelectuais do antiliberalismo: projetos e políticas para outras modernidades. Rio de Janeiro: Civilização Brasileira, 2010.

LAMOUNIER, Bolívar. Formação de um pensamento político autoritário na Primeira República: uma interpretação. In: FAUSTO, Boris (Org). História geral da civilização brasileira, O Brasil republicano. Rio de Janeiro: Bertrand Brasil, 2006. Tomo III.
ODÁLIA, Nilo. As formas do mesmo: ensaios sobre o pensamento historiográfico de Varnhagen e Oliveira Viana. São Paulo: Unesp, 1997.

RICUPERO, Bernardo. O conservadorismo difícil. In: FERREIRA, Gabriela Nunes; BOTELHO, André (Org.). Revisão do pensamento conservador: ideias e política no Brasil. São Paulo: Hucitec, 2010. p. 76-94.

VIANA, Oliveira. Populações meridionais do Brasil. São Paulo: Monteiro Lobato \& Cia, 1920.

. O Idealismo na evolução política do Império e da República. São Paulo: Biblioteca de O Estado de São Paulo, 1922.

Evolução do povo brasileiro. São Paulo: Monteiro Lobato \& Cia, 1923.

O idealismo da Constituiçãa. Rio de Janeiro: Terra e Sol, 1927.

. Problemas de política objetiva. São Paulo: Companhia Editora Nacional, 1930.

O idealismo da Constituição. 2. ed. Rio de Janeiro: Companhia Editora Nacional, 1939.

. Problemas de Direito Corporativo. Brasília: Câmara dos Deputados, 1938.

. Problemas de direito sindical. Rio de Janeiro: Max Limonad, 1943.

Instituições PolítQicas Brasileiras. Rio de Janeiro: José Olympio, 1949.

. Problemas de organização e problemas de Direção. Rio de Janeiro: José Olympio, 1952.

VIEIRA, Evaldo. Autoritarismo e corporativismo no Brasil. São Paulo: Cortez, 1981. 